\title{
Clíticos dativos em cartas pessoais do Ceará do século XX
}

\author{
Dative forms in personal letters of Ceará, Brazil, of 20th century
}

Francisco Jardes Nobre de Araújo', Hebe Macedo de Carvalho ${ }^{2}$

Doutorando em Linguística pelo Programa de PósGraduação em Linguística da Universidade Federal do Ceará, autor de A variação te//he em cartas pessoais de cearenses no século XX. 2014. 151f. Dissertação (Mestrado em Linguística). E-mail: jardsnobre@hotmail.com

Professora do Departamento de Letras Vernáculas e do Programa de Pós-Graduação em Linguística trablhos nárea da Sociolingústica E-mail: macedohebe@hotmail.com.
RESUMO: 0 artigo analisa a alternância dos pronomes 'te' e 'lhe' como oblíquos dativos de $2^{a}$ pessoa em cartas pessoais cearenses, escritas durante o século XX, tendo como pressupostos teórico-metodológicos a Sociolinguística Variacionista (LABOV, 1972, 1994) e os princípios gerais da Sociolinguística Histórica (CONDE SILVESTRE, 2007). A amostra analisada compõe-se de 186 cartas pessoais escritas por cearenses. Na análise da variação, considera-se a atuação dos grupos de fatores tipo semântico do verbo; estrutura do verbo da oração; posição do clítico na oração e as variáveis extralinguísticas década em que as cartas foram escritas e sexo do remetente. Como ferramenta para mensuração dos dados, utilizou-se o programa computacional GoldVarb X (SANKOFF; TAGLIAMONTE; SMITH, 2005). Concluiu-se que, nas cartas da amostra, a forma mais frequente foi 'Ihe', que a posição do pronome tem forte influência sobre a escolha do clítico e que a variação 'te' 'Ihe' se mostra estável ao longo do século XX na variedade do português usada na escrita de cearenses, não sinalizando, portanto, para uma futura mudança com predomínio de uma das duas formas. Palavras-chave: Variação pronominal; Clíticos 'te' e 'lhe'; Cartas pessoais; Sociolinguística Histórica; Sociolinguística Variacionista.

ABSTRACT: The article analyzes the alternation of the pronouns te and lhe in the function of dative for 2nd person, in personal letters of the state of Ceará, Brazil, written during the 20th century, with the theoretical and methodological assumptions of Variationist Sociolinguistics (LABOV, 1972, 1994) and the general principles of Historical Sociolinguistics (Conde Silvestre, 2007). The sample consists of 186 personal letters written. In the analysis of such variability, some groups of factors were considered: semantic type of the verb; structure of the verb; position of the clitic; and extralinguistic variables decade in which the letters were written and sex of the sender. As a methodological tool, it was used the computer program GoldVarb X (Sankoff; Tagliamonte and Smith, 2005). It was concluded that, in the letters of the sample, the most common form was 'lhe', that the position of the clitic has a strong influence on the choice of it, and the alternation 'te' ' 'lhe' is stable throughout the $20^{\text {th }}$ Century in the variety of Portuguese used in Ceará, not signaling therefore for a future change with the predominance of one of two forms.

KEYWORDS: Pronominal variation; ‘Te’ and 'lhe' forms; Personal letters; Historical Sociolinguistics; Variationist Sociolinguistics. 


\section{Introdução}

$\mathrm{P}$

ara o dativo da $2^{\underline{a}}$ pessoa do singular, a língua portuguesa herdou da

língua latina a forma átona 'te' $(<t i<t i b i)$, além da forma tônica 'ti', de mesmo étimo, usada, para essa função, com as preposições 'a' ou 'para'. A primeira dessas formas, na fase moderna da língua, entrou em concorrência com 'Ihe' (< lhi, li $<^{*}$ eli < Illi), oblíquo dativo de $3^{\text {a }}$ pessoa para substituir expressões de tratamento como 'o senhor', 'Vossa Mercê', 'Vossa Senhoria' etc.

Assim, diferentemente de 'te', que tem como referência o interlocutor, mesmo que de forma genérica, 'Ihe' tanto pode ser usado para $3^{\text {a }}$ quanto para a $2^{\underline{a}}$ pessoa.

Entretanto, conforme Bagno (2011), o único uso que se observa de 'lhe' no português brasileiro falado é o de referência à $2^{\mathrm{a}}$ pessoa, de modo que sua referência à $3^{\underline{a}}$ só persiste nos gêneros mais formais da modalidade escrita.

Para Marcuschi (2001, p. 38), em cartas pessoais, gênero que se aproxima da oralidade pelo tipo de linguagem e pela natureza da relação entre os indivíduos, temos a possibilidade de verificar muitos dos aspectos comuns na fala espontânea. Por essa razão, partimos da observação de correspondências privadas para a análise da variação 'te' ' 'lhe' com função de dativo, além de que, nesse gênero, é bastante comum o remetente dirigir-se a seu interlocutor (o destinatário) através de uma forma pronominal, seja do caso reto ('tu', 'você', 'o senhor' etc.), seja do caso oblíquo ('te', 'ti', 'lhe' etc.).

Os exemplos abaixo, retirados de uma mesma carta da amostra, ilustram a variação aqui analisada:

(01) Comunico-LHE o recebimento de Vossa carta. [C003]

(02) pessu-TE desculpa dos eros e da letra. [C003]
A amostra ${ }^{1}$ analisada é composta de 186 cartas, redigidas entre 1940 e 1999, por pessoas não ilustres, que viveram e/ou ainda vivem no estado do Ceará. São todas correspondências de cunho pessoal enviadas para parentes, amigos ou alguém íntimo - namorado(a), noivo(a), marido/mulher. Embora não tenha sido considerado como grupo de fator de variação o subgênero da carta pessoal na pesquisa, têm-se na amostra cartas de família, cartas de amigo, cartas de amor. Do total, 94 cartas têm autoria masculina e 92 têm autoria feminina.

No Brasil, têm sido realizados trabalhos de natureza sociolinguística (SOTO, 2001; LOPES, 2004; LOPES, MACHADO, 2005; SALES, 2007; ANDRADE, 2011; RUMEU, 2004, 2013, dentre outros) cujos corpora são cartas pessoais, apesar das dificuldades em coletar material escrito a mão e/ou datilografado de autoria popular, como uma carta pessoal, um bilhete ou um cartão postal, pois tais documentos costumam ser destruídos tão logo perdem a importância afetiva ou são de difícil acesso ao pesquisador devido ao caráter íntimo que faz com o que seus donos não os compartilhem para estudos. Somente o acaso pode pôr nas mãos do pesquisador documentos de natureza pessoal pertencentes a sincronias passadas, diferentemente do que ocorre com bancos de dados sincrônicos, por exemplo, em geral planejados e constituídos previamente para o fim da pesquisa científica. Quanto aos documentos históricos, Labov (1994, p. 11) afirma que eles, além de, muitas vezes, não favorecerem a localização de informações precisas acerca da caracterização do perfil social dos autores, nem sempre refletem os legítimos traços de sua língua vernacular.

O presente estudo objetiva, de modo geral, apresentar uma análise acerca da variação entre as formas 'te' e 'lhe' na função de dativo com referência à $2^{\underline{a}}$ pessoa do singular em cartas pessoais novecentistas. Controlamos três

A amostra de cartas pessoais usada neste estudo foi coletada para a dissertação de Araújo (2014). 
variáveis linguísticas, já testadas em estudos com variação dos clíticos, a saber: tipo semântico do verbo (ARAÚJO, 2014; ARAÚJO; CARVALHO, 2015); estrutura do verbo da oração (ARAÚJO, 2014; SOUZA, 2014; BIAZOLI 2016); posição do clítico na oração (ARAÚJO, 2014; SOUZA, 2014); e duas variáveis extralinguísticas: a década em que as cartas foram escritas e o sexo do remetente.

Tendo sido verificada em dados orais em estudos anteriores (ALMEIDA, 2009; LOPES, CAVALCANTE, 2011), a variação 'te' 'lhe' dativo em dados escritos é, portanto, o foco deste estudo, que se interessa por investigar como tal fenômeno se deu ao longo do século XX no português escrito usado por cearenses, qual a relação entre tal variação e o sexo do remetente e como os fatores linguísticos selecionados interferem na escolha de uma das formas em variação.

Após a leitura atenta de cada carta da amostra, as ocorrências de 'te' 'Ihe' foram armazenadas digitalmente, codificadas e submetidas à análise através do GoldVarb X, pacote de programas computacionais bastante utilizado em pesquisas de Sociolinguística Variacionista (SANKOFF; TAGLIAMONTE; SMITH, 2005).

A seguir, serão apresentados os pressupostos teóricos (seções 1 e 2), os procedimentos metodológicos adotados (seção 3) e os resultados da análise (seção 4), além das considerações finais.

\section{Pressupostos teóricos}

O estudo aqui apresentado insere-se no conjunto de trabalhos da área da Sociolinguística Histórica (CONDE SILVESTRE, 2007), ancorado nos estudos labovianos, sobre a variação pronominal no português brasileiro. Para Labov (1972; 1994), a língua mantém com a sociedade uma relação de influência mútua, de modo que cada um desses sistemas, heterogêneos por natureza, reflete as mudanças que ocorrem no outro. Assim, constantes forças linguísticas/internas e extralinguísticas/externas condicionam as línguas humanas e refletem o funcionamento dinâmico destas. Tal funcionamento, embora heterogêneo, é estruturado, ordenado e passível de ser estudado.

A heterogeneidade ordenada das línguas, quer sincronicamente, quer diacronicamente, é uma das concepções básicas defendidas por Weinreich, Labov e Herzog (2006 [1968]) que lançaram as bases para uma abordagem inerentemente histórica e social aos estudos da linguagem.

Weinreich, Labov e Herzog (2006 [1968]) concebem a variável linguística como uma representação abstrata do percurso realizado pela concorrência entre duas ou mais formas variantes motivada simultaneamente por fatores linguísticos e extralinguísticos passíveis de quantificação estatística. Considerando que as gramáticas em que ocorre uma mudança linguística são gramáticas de comunidades de fala, os autores defendem ser necessário que o estudo da natureza heterogênea sistemática da língua se oriente pelo princípio que dissocia a estrutura linguística da homogeneidade e descreva de forma ordenada as variações que ocorrem numa língua que serve à comunidade na qual é usada.

A Teoria da Variação e Mudança Linguística concebida por Weinreich, Labov e Herzog (2006 [1968]) considera que as línguas naturais são continuações históricas que acompanham as gerações sucessivas de indivíduos, sendo as mudanças que ocorrem numa língua ao longo do tempo resultados da variação entre as formas linguísticas durante certo período. Os estudos de Sociolinguística variacionista têm como alguns problemas centrais: (i) investigar quais restrições/condicionamentos linguísticos atuam na variação e mudança linguística; (ii) descrever como são observadas o encaixamento das mudanças, em ambas as estruturas linguística e social; (iii) analisar quais fatores podem explicar a atuação da mudança linguística, com causas provenientes do estímulo e das restrições sociais e da estrutura 
linguística. Labov (1994) afirma que há casos de variação estável em que uma determinada variante permanece, ao longo dos séculos, refletindo comportamento linguístico do indivíduo estável por todo o tempo de sua vida, e a comunidade, consequentemente, permanece estável; não havendo, portanto, variação para analisar. Assim, a variação estável na comunidade de fala não envolve mudança.

Localizar documentos que sobreviveram às intempéries do tempo e que atendam as exigências da pesquisa é a principal dificuldade enfrentada por quem se dedica a estudar sincronias linguísticas passadas através de textos não publicados, como cartas. Outra dificuldade é que, muitas vezes, os documentos localizados não deixam claros os aspectos sociais dos autores, exigência fundamental em estudos de natureza sociolinguística. Labov (1994, p. 11) afirma que, embora se saiba que o que foi escrito, não se sabe nada acerca do que foi entendido nem se tem condições nenhumas de desenvolver experimentos controlados sobre a compreensão transdialetal. Para ele, trabalhando com documentos antigos, "nosso conhecimento do que era distintivo e do que não era é severamente limitado, uma vez que não podemos usar o conhecimento dos falantes nativos para diferenciar variantes distintivas de não distintivas." 2

Conde Silvestre (2007), ampliando a discussão de Labov acerca das dificuldades de se trabalhar com fontes escritas remotas, acrescenta que os dados históricos do passado são insatisfatórios para a descrição empírica por vários motivos:

Em primeiro lugar, porque se conservaram no meio escrito; esta circunstância (...) faz com que os textos apareçam muitas vezes ilhados e desprovidos dos componentes do contexto e situação em que se originaram

\footnotetext{
2 No original: "Our knowledge of what was distinctive and what was not is severely limited, since we cannot use the knowledge of native speakers to differentiate nondistinctive from distinctive variants" (Tradução nossa).
}

(...). Em segundo lugar, os textos do passado são meros restos de corpora textuais muitíssimo mais amplos, que sobreviveram por acaso, daí, segundo Labov, seu caráter fragmentário; deste modo, em geral, nem todos os estilos, registros ou as variedades vinculáveis ao passado das línguas estão representados no conjunto de textos que se conservam, e a própria quantidade e diversidade dos dados sobreviventes varia enormemente de uns períodos a outros por circunstâncias totalmente aleatórias. Tampouco está testemunhada a produção de falantes pertencentes a todos os níveis sociais de comunidades históricas, pois, até pouco tempo, somente os falantes masculinos de classe média a alta tinham acesso à escrita. (CONDE SILVESTRE, 2007, p. 35-6) ${ }^{3}$

Todas estas dificuldades apresentadas pelo autor nos foram impostas, como se verá na seção em que descrevemos a amostra, de modo que tivemos de nos esforçar para tirar o melhor proveito possível dos "maus dados", como aconselha Labov (1994) ao tratar da Linguística Histórica.

A Linguística Histórica, segundo Labov (1994, p. 11), pode ser pensada como "a arte de fazer o melhor uso dos maus dados", e os documentos históricos tanto são valiosos porque mostram, de alguma forma, o modo como a língua era usada em determinada época, quanto são empobrecidos porque esses documentos sobrevivem por acaso, não por intenção, de modo que a seleção disponível é o produto de uma série imprevisível de acidentes históricos. Para ele,

\footnotetext{
${ }^{3}$ No original: "En primer lugar porque se han conservado en el medio escrito; esta circunstancia (...) hace que los textos aparezcan muchas veces aislados y desprovistos de los componentes del contexto y situación en que se originaron (...). En segundo lugar, los textos del pasado son meros restos de corpus textuales muchísimo más amplos, que han sobrevivido por azar, de ahí, según Labov, su caráter fragmentario;de esto modo, en general, no todos los estilos, registros, las variedades vinculables al pasado de las lenguas están representados en los textos que se conservan, y la propia cantidad y diversidad de los datos supervivientes varía enormemente de unos conservan, y la propia cantidad y diversidad de los datos supervivientes varía enormemente de unos períodos a otros por circunstancias totalmente aleatorias. Tampoco está atestiguada la producción de hablantes pertenecientes a todos los niveles sociales de comunidades históricas, pues, hasta hace poço tiempo, sólo los hablantes masculinos de rango médio a elevado tenían acceso a la escritura."
} 
As formas linguísticas em tais documentos são frequentemente distintas do vernáculo dos autores e, em vez disso, refletem esforços de captar um dialeto normativo que nunca foi a língua nativa de nenhum falante. Como resultado, muitos documentos são marcados com os efeitos da hipercorreção, da mistura de dialetos e de erros do escrevente (LABOV, 1994, p. 11 - tradução nossa). ${ }^{4}$

Constituindo alternativas interessantes de se conhecer sincronias passadas, os documentos antigos - sobretudo cartas pessoais - têm sido usados como corpus de análise em diversos estudos diacrônicos ou de estágios do português brasileiro em épocas anteriores àquela coberta por projetos de gravação e formação de bancos de dados da fala de determinadas capitais e cidades menores, dos quais são exemplos o de Sales (2007), o de Oliveira e Lopes (2007), o de Andrade (2011), o de Silva (2011), o de Rumeu (2013) e o de Oliveira (2015).

As cartas pessoais têm sido consideradas documentos históricos importantes para o estudo da variação e mudança linguística nos estudos da Sociolinguística Variacionista com dados de língua escrita, uma vez que são correspondências realizadas de uma pessoa para outra apresentando, assim, marcas de tratamento dispensadas pelo remetente ao destinatário, além de usos que caracterizam a variedade linguística empregada pelo autor, sobretudo quando são escritas numa linguagem menos monitorada, mais coloquial ou, conforme Rumeu (2011, p. 112), por serem textos mais "soltos" em relação aos preceitos da norma padrão, o que favorece o aparecimento de formas em competição.

O estudo aqui apresentado desenvolve-se à luz dos pressupostos sociolinguísticos acima apresentados, buscando analisar os possíveis

\footnotetext{
${ }^{4}$ No original: "The linguistic forms in such documents are often distinct from the vernacular of the writers, and instead reflect efforts to capture a normative dialect that never was any speaker's native language. As a result, many documents are marked with the effects of hypercorrection, dialect mixture, and scribal error"
}

condicionadores linguísticos e extralinguísticos da variação das formas pronominais 'te' e 'lhe' com função de dativo em cartas pessoais novecentistas escritas por cearenses.

\section{Sobre as formas pronominais 'te' e 'lhe' dativas}

As relações sociais podem ser simétricas ou assimétricas. Brown e Gilman (1960) chamam as primeiras de relações de "solidariedade" quando os interlocutores apresentam condições sociais comuns (mesma faixa etária, mesmo status social etc.) ou certo grau de intimidade entre si - e as segundas de relações de "poder" - quando um dos interlocutores ocupa uma posição superior, seja pela idade, seja pelo status social, seja pela ocupação de um cargo, seja pela força física. Para eles, tais relações são refletidas na linguagem através das formas usadas por um interlocutor para se dirigir ao outro:

Pode-se dizer que uma pessoa tem poder sobre outra na medida em que ela é capaz de controlar o comportamento da outra. O poder é um relacionamento entre, no mínimo, duas pessoas e é não recíproco no sentido de que ambos não podem ter poder na mesma área de comportamento. 0 poder semântico é, de forma semelhante, não recíproco; o superior usa T e é tratado por V. (BROWN; GILMAN, 1960, p. 255 - tradução nossa) ${ }^{5}$

As letras $\mathrm{T}$ e $\mathrm{V}$ mencionadas na citação acima vêm, respectivamente, de $t u$ e vos, em latim, quando tu era usado para uma pessoa íntima ou socialmente inferior e vos para uma pessoa não íntima ou socialmente superior. Observando o uso de pronomes distintos nas relações de poder e nas

5 No original: "One person may be said to have power over another to the degree that it is able to contro the behavior of the other. Power is a relationship between in the sense that both cannot have power in the same area of behavior. The semantic power is similarly non-reciprocal, the superior uses T and receives V." 
relações de solidariedade em diversas línguas, Brown e Gilman elaboraram a Teoria T-V, segundo a qual as línguas codificam lexicalmente as relações entre os interlocutores; assim, nas relações simétricas e nas assimétricas respectivamente, usam-se $d u$ e Sie em alemão, tu e vous em francês, tu e Lei em italiano, tú e Usted em espanhol europeu etc.

No caso do português, a codificação dessas relações dava-se, até o séc. XV (cf. AMARAL, 1955) pelas formas 'tu' (forma T) e 'vós' (forma V), cada uma com suas respectivas formas oblíquas e possessivas: 'te', 'ti', 'contigo', 'teu' como formas T e 'vos', 'convosco', 'vosso' como formas V. Já em fins do referido século, 'vós' como forma $\mathrm{V}$ havia se tornado obsoleto, tendo sido substituído pela expressão 'vossa mercê', com oblíquos e possessivos de $3^{\text {a }}$ pessoa ('o'/'a', 'lhe', ‘se', 'si', 'consigo', ‘seu'), a qual “seguiu uma trajetória de modificação de valor ao lado da modificação fonética” (MENON, 1995, p. 65), resultando em 'você'. No português brasileiro, a distinção de valor entre 'tu' e 'você' se perdeu na língua falada, de modo que ambas as formas, em algumas regiões (p. ex. no Nordeste, cf. GUIMARÃES, 2014), podem aparecer na mesma situação comunicativa com os mesmos referentes.

A competição entre as formas T e as formas V, segundo Duarte (1993), acentuou-se nas primeiras décadas do século passado, resultando em variações diversas ('tu' 'você', 'te' $\sim$ 'lhe', 'teu' 'seu' etc.) verificadas praticamente em todo o território brasileiro. A autora, que analisou o preenchimento do sujeito de $1^{\mathrm{a}}, 2^{\mathrm{a}}$ e $3^{\mathrm{a}}$ pessoas em textos teatrais durante o período de 1845 até 1992, concluiu que a distinção entre as formas T e V se atenuou por volta da década de 1930, mesmo período apontado por Rumeu (2013) ao estudar o uso de 'você' em cartas de uma família carioca escritas em fins do século XIX e na primeira metade do século XX.

$O$ estudo aqui apresentado foca na variação 'te' $\sim$ 'lhe', bastante frequente em muitas regiões do Brasil. Em algumas áreas, predomina o uso de 'te', como em São Paulo (RAMOS, 1997) e em grande parte de Minas Gerais (MOTA,
2008), justamente nas regiões onde 'tu' caiu em desuso; em outras, como no Ceará (ARAÚJO, 2014) e na Bahia (ALMEIDA, 2009), predomina o uso de 'Ihe', embora 'tu' seja bastante frequente.

As gramáticas tradicionais prescrevem o uso de 'lhe' apenas como objeto indireto com referência a pessoas, respeitando sua origem latina (de $\breve{l l l i}$, dativo do demonstrativo ǐlle, "aquele", fonte do pronome português 'ele'). Entretanto, alguns autores, como Monteiro (1994) e Nascentes (2003), atestam seu uso também como objeto direto. Em Araújo e Carvalho (2015), a mesma amostra aqui analisada serve como corpus para um estudo acerca da variação 'te' 'lhe' na função de acusativo (objeto direto). 0 exemplo que segue foi retirado dessa amostra e exemplifica a referida variação:

(03) Você não imagina como LHE esperei na agência [...] Não sei bem o que eu faria se algum dia eu TE reencontrasse. [C058]

Note-se, em (03), que a forma 'lhe' assume valor de $2^{\underline{a}}$ pessoa, aparecendo em variação com a forma 'te' numa mesma carta.

Além do uso acusativo, outro uso de 'lhe' tem contrariado a gramática normativa, que é sua referência unicamente à $2^{\underline{a}}$ pessoa na língua falada. Tanto Araújo e Carvalho (2015) quanto Sales (2007, p. 66) só encontraram 'Ihe' com referência à $2^{\underline{a}}$ pessoa, o destinatário, nas cartas analisadas nas respectivas pesquisas.

O uso de você (contração da expressão de tratamento cerimonioso 'Vossa Mercê') com referência à $2^{\text {a }}$ pessoa alterou "substancialmente o comportamento do preenchimento dos sujeitos ao longo do século $\mathrm{XX}$, visto que o aumento da frequência de uso das formas plenas está intimamente ligado ao aumento da produtividade do você" (MACHADO, 2006, p. 99). Tendo 'você' entrado em competição com 'tu' e, assim, adquirido também a função de forma T, passou-se a recorrer a expressões nominais para substituir as formas V. Como bem afirma Lopes (2007, p. 116), "a implementação de 
'você' e 'a gente' no sistema de pronomes pessoais gerou uma série de reorganizações gramaticais, tanto no subsistema de possessivos, quanto no de pronomes que exercem função de complementos diretos ou indiretos".

A autora discorda da prescrição normativa da uniformidade de tratamento, pois defende que a combinação entre as formas do paradigma de 'tu' e as formas do paradigma de 'você' já se tornou uma característica muito natural do português brasileiro.

Lopes e Cavalcante (2011, p. 35) defendem que, em decorrência da variação 'tu' e 'você', que ocorre de forma variável em diversas regiões brasileiras (com predomínio de 'tu' em algumas áreas, de 'você' em outras, ausência de variação em outras), todas as formas oblíquas e possessivas de tais pronomes apresentam variação (nominativo: 'tu' 'você'; acusativo:

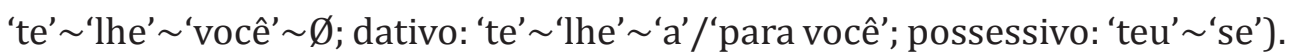

Como se percebe, as autoras apontam que ocorre variação no dativo não só entre as formas oblíquas ('te' e 'lhe'), mas também entre estas e sintagmas preposicionados, os quais, por sua vez, também apresentam variação quanto ao uso da preposição ('a' ou 'para'). Em nossa pesquisa, focamos somente na variação entre as formas oblíquas mencionadas.

Nascentes (2003, p. 447), acerca do uso de 'lhe', diz que seu emprego dativo se atenuou, sendo as expressões 'a ele', 'para ele', 'a você' e 'para você' preferíveis na língua falada.

Levando em conta tudo o que foi exposto, buscamos investigar e apresentar neste artigo em que medida as cartas escritas por cearenses retratam a alternância 'te' ' 'lhe' com função de dativo, qual a tendência de uso e que motivações linguísticas e sociais, como os anos em que os textos foram escritos e o sexo dos remetentes influenciam na ocorrência dessa variação.

Na seção seguinte, detalhamos a metodologia empregada para a coleta e a codificação das cartas que constituem o corpus desta pesquisa.

\section{Procedimentos metodológicos}

O corpus da pesquisa aqui apresentada constitui-se de 186 documentos escritos, no século XX, cuja composição obedeceu aos critérios de ser do gênero carta pessoal e ser de autoria de cearenses não ilustres. Durante a coleta, os detentores das cartas forneceram algumas informações relacionadas aos remetentes (faixa etária; a naturalidade e o tempo de moradia no Ceará; assunto; a relação com o destinatário, etc.).

Quanto à função dos pronomes em variação, consideramos dativo, conforme Camara Jr. ([1970] 2015, p. 118), o pronome que expressa "um ponto terminal de referência" podendo ser parafraseado por um substantivo ou um pronome substantivo por intermédio da preposição 'a' (ou 'para'). Assim, os pronomes na função de dativo são empregados:

a) com VIs ou com VTIs ou que regem as preposições 'a' ou 'para', indicando atribuição ('ocorrer a', 'acontecer a', pertencer a', 'caber a' etc.) ou interesse ('importar a', 'interessar a' etc.);

b) com VTDIs que expressam entrega ('dar algo a', 'entregar algo a', 'doar algo para' etc.) ou apresentação ('apresentar algo a', 'mostrar algo a', 'indicar algo a' etc.);

c) indicando a quem se destina o objeto direto, independentemente do verbo (ex. "Assar um bolo para alguém" $\rightarrow$ "Assar-lhe um bolo");

d) indicando a quem pertence o objeto direto, independentemente do verbo (ex.: "Acariciar-te os cabelos");

e) com certos substantivos e adjetivos, como complemento destes ('amor a', 'útil a').

Todas as ocorrências dos clíticos 'te' e 'lhe' da amostra em estudo foram computadas somente quando atendiam a um dos casos acima descritos. 


\subsection{Descrição da amostra}

A amostra utilizada na presente pesquisa compreende 186 cartas pessoais das quais a mais antiga data de 07 de janeiro de 1940 e a mais recente é de 08 de dezembro de 2000. As cartas foram distribuídas em três pares de décadas, a saber: anos 1940/50 (26 cartas), anos 1960/70 (80 cartas) e anos 1980/90 (80 cartas).

Como se percebe, não conseguimos distribuir ortogonalmente as cartas em células referentes ao período em que elas foram escritas, uma vez que encontramos poucas cartas do primeiro par de décadas em comparação com as cartas dos demais pares. Também não conseguimos distribuir as cartas em quantidades iguais ou aproximadas em células referentes à faixa etária, à escolaridade, ao grupo social, à relação remetente-destinatário. Dos aspectos extralinguísticos, a única organização mais equilibrada possível de se fazer foi quanto à autoria das cartas, pois conseguimos dispô-las nas duas categorias de forma equilibrada: cartas de autoria masculina (14 nos anos 1940/50, 40 nos anos 1960/70 e 40 nos anos 1980/90) e cartas de autoria feminina (12 nos anos 1940/50, 40 nos anos 1960/70 e 40 nos anos 1980/90). O Quadro 1 ilustra a organização que fizemos da amostra:

Quadro 1 - Amostra de cartas pessoais cearenses por décadas

\begin{tabular}{|c|c|c|c|c|}
\hline \multicolumn{5}{|c|}{ Cartas pessoais cearenses } \\
\hline Autoria $\quad$ Períodos & $1940 / 50$ & $1960 / 70$ & $1980 / 90$ & Total \\
\hline Masculino & 14 & 40 & 40 & \\
\hline Feminino & 12 & 40 & 40 & \\
\hline Total & 26 & 80 & 80 & 186 \\
\hline
\end{tabular}

Passemos agora a detalhar as variáveis linguísticas e extralinguísticas consideradas durante a análise dos dados.

\subsection{Variáveis}

\subsubsection{Variável dependente}

A variável dependente é a alternância entre os clíticos dativos 'te' e 'lhe' com função de $2^{\underline{a}}$ pessoa.

\subsubsection{Variáveis independentes}

As variáveis linguísticas controladas na análise foram três: a) posição do clítico (verbo na $1^{a}$ posição absoluta, próclise após conjunção, próclise após advérbio, próclise após substantivo, próclise após pronome, próclise após verbo auxiliar, próclise após preposição, ênclise); b) tipo semântico do verbo (verbos de atividade, cognitivos, dicendi, existenciais, materiais, perceptivos, relacionais, sentimentais); e c) estrutura do verbo da oração (forma simples, forma perifrástica).

Essas três variáveis serão explicitadas a seguir:

\section{a) Posição dos clíticos}

Os vocábulos 'te' e 'lhe' são denominados "clíticos" em razão de serem átonos e se apoiarem em outro vocábulo, antes ou depois dele "para, juntos, constituírem um único grupo acentuado" (BAGNO, 2011, p. 740). Conforme Bagno (2011), tais vocábulos, na sincronia atual do português brasileiro, apresentam apenas duas posições em relação ao verbo: antes (próclise) ou depois (ênclise).

Pagotto (1992), Coelho (2003) e Schei (2003) realizaram pesquisas sobre a colocação pronominal no português brasileiro e concluíram que a tendência geral é a próclise, usando-se a ênclise apenas em textos formais, em discursos monitorados e em certas expressões idiomáticas (p. ex. “Valei-me!”, “Dane-se!”, “Danou-se!” etc.). Assim, consideramos a hipótese de que 'lhe', por ainda conservar o traço [+formal], ocorre em posição enclítica, que também porta o traço [+formal], conforme as autoras. 
Estudando a colocação pronominal no português europeu e no português brasileiro, Cavalcante, Duarte e Pagotto (2011) apresentam uma tipificação dos casos de posição do clítico a qual adaptamos para esta pesquisa:

a) Próclise em início de oração (absoluta, principal ou subordinada reduzida):

(04) TE desejo felizes dias de vida [C165]

b) Próclise após conjunção:

(05) pedimos ao nosso bondoso Deus que LHE conceda uma outra oportunidade [C043]

c) Próclise após advérbio:

(06) agora TI pergunto [C122]

d) Próclise após substantivo:

(07) Os meus filhos TE pedem a bençam [C004]

e) Próclise após pronome:

(08) eu TE escrevo estas pocas linha [C061]

f) Próclise após verbo auxiliar:

(09) O J. tem LHE escrito? [C002]

g) Próclise após preposição:

(10) Há dias era para LHE escrever [C126]

h) Ênclise:

(11) Comunicu-TE o recebimento de sua carta [C001]

b) Tipo semântico do verbo

Esse grupo de fatores foi definido conforme a proposta de Scheibman (2000), que categoriza os verbos nos seguintes tipos semânticos: a) verbos de cognição (cognitivos): os que descrevem alguma atividade mental, como 'conhecer', 'saber', 'pensar', 'lembrar', 'esquecer', 'decorar' etc.;

b) verbos de atividade corporal: os que descrevem gestos ou interações corporais, como 'comer', 'beber', 'dormir', 'fumar' etc.;

c) verbos existenciais: os que expressam existência ou acontecimento, como 'ser', 'acontecer', 'ocorrer', 'estar', 'haver' etc.;

d) verbos de sentimento (sentimentais): os que indicam emoção, desejo, como 'sentir', 'querer', 'desejar', 'necessitar' etc.;

e) verbos materiais: os que se referem a ações ou atitudes concretas ou abstratas, como 'fazer', 'ir', 'ensinar', 'trabalhar', 'usar', 'brincar' etc.;

f) verbos de percepção (perceptivos): os que indicam percepção ou atenção, como olhar, ver, ouvir, encontrar etc.;

g) verbos possessivos/relacionais: os que indicam posse ou pertinência, como 'ter', 'possuir', 'pertencer', 'condizer' etc.;

h) verbos relacionais: os que expressam uma característica do ser, como 'ser', 'parecer', 'tornar-se', 'ficar' etc.;

i) verbos dicendi: os que indicam ações verbais, como 'dizer', 'falar', 'perguntar', 'exclamar', 'prometer' etc.

Como a presente pesquisa foca nos clíticos dativos, sua ocorrência se torna mais comum com verbos dicendi e com verbos materiais, uma vez que os demais tipos normalmente exigem um clítico acusativo como complemento. Partimos da hipótese de que os verbos dicendi favorecem o uso de 'lhe' por expressarem certo distanciamento entre os interlocutores, adequando-se assim a um pronome que se usava inicialmente como forma de cortesia.

\section{c) Estrutura do verbo da oração}

Para esta pesquisa, codificamos os verbos, quanto à estrutura, em formas simples ('escrevo') e em formas perifrásticas ('tenho escrito', ‘devo escrever') 
e aventamos a hipótese de que a forma 'lhe' seria mais usual com formas perifrásticas, que são mais recentes no idioma.

Exemplos de 'te'/'lhe' dativo com formas simples nas cartas:

(12) Comunicu-TE o recebimento de sua carta. [C001]

(13) Comunico-LHE o recebimento de Vossa carta. [C003]

Exemplos de 'te'/'Ihe' com formas perifrásticas nas cartas:

(14) I. vai LHE escrever algumas cousas. [C002]

(15) estou TE escrevendo. [C098]

\subsection{Variável extralinguística}

Devido às dificuldades impostas pela natureza do corpus, como já comentamos anteriormente, não nos foi possível considerar os aspectos sociais dos autores, de modo que apenas duas variáveis extralinguísticas foram levadas em conta na análise: a década e o sexo do remetente.

\subsubsection{Décadas em que as cartas foram escritas}

$\mathrm{Na}$ amostra, as cartas foram estratificadas por décadas e sexo dos remetentes.

As cartas estão estratificadas pelas seguintes décadas:

a) Décadas de 1940 e 1950;

b) Décadas de 1960 e 1970;

c) Décadas de 1980 e 1990 .

A nossa expectativa era de que uso de 'lhe' com referência à $2^{\text {a }}$ pessoa em alternância com o uso de 'te' tivesse aumento de frequência ao longo das décadas nas cartas cearenses.

\subsubsection{Sexo do remetente}

Partimos do pressuposto teórico-metodológico da Sociolinguística Variacionista de que homens e mulheres se expressam de maneira diferente, buscamos compreender qual a atuação do sexo do remetente na variação das formas pronominais 'te' e 'lhe'.

a) Cartas de homens (94)

b) Cartas de mulheres (92)

Nossa hipótese, antes de realizarmos a análise, era a de que nas cartas de mulheres ocorreriam mais 'te' do que nas cartas de homens.

\section{Análise das formas te lhe em cartas cearenses}

Ao todo, foram coletadas 320 ocorrências de 'te' e 'lhe' dativos, distribuídas conforme a Tabela 1.

Tabela 1 - Frequência de uso de 'te' e The' como dativo nas cartas cearenses

\begin{tabular}{ccc}
\hline Formas & Ocorrências/Total & $\%$ \\
'te' & $147 / 320$ & 46 \\
'lhe' & $173 / 320$ & 54 \\
\hline
\end{tabular}

Segundo a Tabela 1, percebemos uma variação acirrada entre as formas clíticas na função de dativo, com predomínio de 'lhe'.

Feita a rodada através do GoldVarb X, o programa selecionou como variáveis significativas dois grupos de fatores: a posição do clítico e o tipo semântico do verbo.

Ressalte-se que predomina nas cartas cearenses o 'lhe' como pronome de $2^{\text {a }}$ pessoa. No entanto, houve uma única ocorrência desse clítico com referência à $3^{\underline{a}}$ pessoa em uma carta da década de 1940, como comprova o trecho (16): 
(16) disse a D. que quando o M. veio de Mossoró que esteve em Lajes e Angico foi em casa della, D., mas de uma vez seduzi-la não somente com palavras prostituídas, como agindo, dizendo a D. que LHE servise de mulher, pois pretendia formicar com ella, dizendo que a esposa era doente e não podia ficar separado de mulher, o que ella rezistiu muito que a última vez que ELLE a procurou, foi em um estado tão vergonhoso, dizer que ella LHE fizesse isto e ella repreendeu-o, que não seria falda a seu marido [C002]

Esse dado foi excluído da análise por não fazer referência à $2^{\underline{a}}$ pessoa do discurso, objeto de estudo desta investigação. Contudo, essa única ocorrência de 'lhe' de $3^{\text {a }}$ pessoa e somente na primeira década recoberta pela amostra pode significar indícios de mudança na referência do clítico na escrita informal do português brasileiro (BAGNO, 2011), já que não se verificaram mais ocorrências assim nas cartas a partir de 1940.

\subsection{Posição dos pronomes 'te' ' 'lhe' em relação ao verbo}

A Tabela 2 mostra que a posição de próclise favorece o uso da forma 'te' e desfavorece o uso da forma 'lhe'. Contudo, após conjunções (52\%), após advérbios (53\%) e após verbos auxiliares (62\%) o 'lhe' foi mais frequente do que o 'te'. Conferir os resultados desse grupo de fatores na tabela abaixo.

Tabela 2 - Posição dos clíticos 'te' e 'lhe' nas cartas cearenses

\begin{tabular}{lccc}
\hline Posição dos clíticos & 'te' & 'Ihe' & Total \\
Próclise em início de oração & $11(100 \%)$ & $0(0 \%)$ & 11 \\
Próclise após conjunções & $12(48 \%)$ & $13(52 \%)$ & 25 \\
Próclise após advérbios & $17(47 \%)$ & $19(53 \%)$ & 36 \\
Próclise após substantivos & $9(60 \%)$ & $6(40 \%)$ & 15 \\
Próclise após pronomes & $26(63 \%)$ & $15(37 \%)$ & 41 \\
Próclise após verbo auxiliar & $22(38 \%)$ & $36(62 \%)$ & 58 \\
Próclise após preposição & $19(50 \%)$ & $19(50 \%)$ & 38 \\
Ênclise & $31(32 \%)$ & $65(68 \%)$ & 96 \\
Total & $147(46 \%)$ & $173(54 \%)$ & 320 \\
\hline
\end{tabular}

Dos casos de próclise, chama a atenção o predomínio de 'te' (100\%) justamente quando o uso contradiz o que prega a tradição gramatical, que é a colocação do pronome oblíquo em início de oração. Tal uso é bastante comum na fala coloquial e nos gêneros textuais escritos menos monitorados, o que sinaliza para uma harmonia com o traço [+informal] de 'te'. Em outras palavras, na colocação pronominal que caracteriza a escrita menos monitorada, menos formal, o uso de 'te', que sempre foi uma forma T, é exclusivo. São exemplos dessas ocorrências:

(17) ...cujo objetivo é TE remeter esta circular... [C010]

(18) graça ao bom Deus tudo aqui em nosso lar está em paz, TE desejo o mesmo. [C075]

(19) Minhas cunhadas gostaram tanto da senhora e TE acharam bonita, te mandam abraços. [C088]

Exemplos de 'lhe' em ênclise (posição em que esta forma predominou sobre 'te'):

(20) Comunico-LHE o recebimento de Vossa carta. [C003]

(21) Desejamo-LHE Bôs Festas. [C008]

(22) aqual com prazer respondo-LHE. [C034]

Tendo sido a posição do clítico um grupo de fatores selecionado como significativamente pelo programa, apresentamos na Tabela 3, a seguir, os resultados da forma inovadora 'lhe' com função de 2 a pessoa em relação à variável posição: 
Tabela 3 - Uso de lhe quanto à posição em relação ao verbo

\begin{tabular}{lcc}
\hline Posição dos clíticos & 'Ihe' & Peso Relativo \\
Próclise em início de oração & $0 / 11(0 \%)$ & - \\
Próclise após conjunções & $13 / 25(52 \%)$ & 0.467 \\
Próclise após advérbios & $19 / 36(53 \%)$ & 0.467 \\
Próclise após substantivos & $6 / 15(40 \%)$ & 0.374 \\
Próclise após pronomes & $15 / 41(37 \%)$ & 0.292 \\
Próclise após verbo auxiliar & $36 / 58(62 \%)$ & 0.573 \\
Próclise após preposição & $19 / 38(50 \%)$ & 0.441 \\
Ênclise & $65 / 96(68 \%)$ & 0.613 \\
Total & $173 / 320(54 \%)$ & - \\
\hline
\end{tabular}

Os resultados em peso relativo confirmam a ênclise como ambiente linguístico favorecedor da forma 'Ihe', em conformidade com a hipótese de que 'lhe', por ainda conservar o traço [+formal], ocorre em posição enclítica, que também porta esse traço (CAVALCANTE; DUARTE; PAGOTTO, 2011, p. 6).

\subsection{Tipo semântico do verbo}

Ao examinarmos a relação entre o tipo semântico do verbo e o clítico preso a ele com a função de dativo na amostra, partimos da hipótese de que verbos que expressam sentimento ('querer' ${ }^{6}$, 'desejar', 'agradar' etc.) desfavorecem o uso de 'lhe' como $2^{\text {a }}$ pessoa, uma vez que esse pronome, por ter sido muito usado como oblíquo das formas de cortesia ('Vossa Mercê', 'Vossa Senhoria'), carrega ainda traços de formalidade e distanciamento, sendo por isso evitado com verbos que exprimem intimidade e proximidade.

\footnotetext{
"Segundo a gramática tradicional, o verbo "querer", quando significa "estimar", "ter alguém como querido", é transitivo indireto, regendo, portanto, o OI (DAT).
}

A Tabela 4 apresenta os resultados referentes ao tipo semântico do verbo em função do clítico 'lhe'. Ressalte-se que verbos perceptivos, verbos cognitivos e de atividade corporal não ocorreram na amostra na análise em tela.

Tabela 4 - 0 tipo semântico do verbo e o uso do lhe

\begin{tabular}{lccc}
\hline Tipo semântico do verbo & Ocorrências/Total & \% & Peso Relativo \\
Dicendi (dizer, comunicar etc.) & $80 / 137$ & 58 & 0.529 \\
Materiais (fazer, escrever, dar etc.) & $70 / 147$ & 48 & 0.450 \\
Sentimentais (querer, desejar, agradar etc.) & $13 / 23$ & 56 & 0.585 \\
Possessivo-relacionais (pertencer, dever etc.) & $5 / 5$ & 100 & - \\
Existenciais (ser, acontecer etc.) & $4 / 6$ & 68 & 0.729 \\
Atividade corporal (pegar, abraçar, segurar etc.) & $1 / 2$ & 50 & 0.505 \\
Total & $173 / 320$ & 54 & - \\
\hline
\end{tabular}

Conforme a Tabela 4, os verbos mais frequentes nas ocorrências de pronome oblíquo átono dativo são, como já comentado, os verbos dicendi. Nestes, a forma 'lhe' predomina sobre a forma 'te' em 58,4\% dos casos com peso relativo de 0.529 .

Na amostra, identificamos 29 verbos do tipo dicendi dos quais 'comunicar' foi o que mais favoreceu o uso de 'lhe': do total de 12 ocorrências dessa forma verbal, 10 selecionaram o clítico 'lhe'. Já nas 19 ocorrências da expressão 'dar notícia', houve apenas 5 ocorrências de 'lhe'. Exemplos desses usos podem se verificar a seguir.

(23) Comunico-LHE o recebimento de Vossa carta.[C003]

(24) E, por falar nisto, quero comunicar-LHE que tenho pelo menos três viagens para este mês. [C022]

(25) Estou te escrevendo para TE dar uma notícia. [C086] 
(26) A finalidade destas pocas linha e somente para TE dar minhas notícias. [C096]

(27) te escrevo estas linhas somente para TE dar as nossas notícias. [C156]

Exemplos dos poucos usos de 'lhe' com a expressão “dar notícias” são:

(28) Tem esta fins dar-LHE minhas notícias. [C014]

(29) Vou por meio destas poucas linhas é somente para dar-LHI nossas notícias. [C090]

Já a nossa hipótese para os verbos sentimentais ('querer', 'desejar' etc.) não se confirmou na amostra, pois 'lhe' foi mais usado com esses verbos do que 'te', com peso relativo de 0.585 . Exemplos dessas ocorrências são:

(30) ... de que minha pretenção não LHE agrade. [C045]

(31) termino desejando-LHE muitas felicidades. [C068]

(32) Da mana que muito LHE quer bem. [C134]

Apesar do baixo número de ocorrências (6) de verbos existenciais, é possível afirmar que esses verbos foram os que mais favoreceram o uso de 'lhe', com peso relativo (0.729). Foram seis ocorrências apenas, sendo cinco com o verbo 'ser' + adjetivo, casos em que o dativo corresponde ao "complemento nominal" da gramática tradicional. 0 outro caso foi com o verbo 'acontecer', em que o dativo corresponde ao item "a" do que estamos chamando de dativo, conforme explicitado na seção de Procedimentos Metodológicos. Desses seis casos de verbos existenciais, transcrevemos dois:

(33) Sou-LHE devedor [C043]

(34) que tudo de bom LHE aconteça [C067]
Em linhas gerais, do ponto de vista do tipo semântico do verbo da oração, o clítico 'lhe' foi mais frequente com verbos existenciais, verbos sentimentais e verbos dicendi.

\subsection{Estrutura do verbo}

A seguir, apresentamos o grupo de fatores que não foi selecionado pelo GoldVarb X, ou seja, a variável estrutura do verbo ao qual se prende o clítico. Classificamos as formas verbais da amostra em simples e perifrásticas (verbo auxiliar ou modal + forma nominal). As primeiras prevalecem sobre as últimas na amostra, como fica claro na Tabela 5:

Tabela 5 - Frequência de uso da estrutura verbal ao qual se prende o clítico

\begin{tabular}{lcc}
\hline Forma & Ocorrências/Total & \% \\
Simples & $215 / 320$ & 67 \\
Perifrástica & $105 / 320$ & 33 \\
\hline
\end{tabular}

Ao analisarmos o uso dativo de 'te' 'lhe' em estruturas verbais simples ou perifrásticas, partimos da hipótese de que estas, por serem mais recentes no idioma (SERAFIM, 2008), favoreceriam o uso de 'lhe', que é uma forma mais recente para a $2^{\text {a }}$ pessoa do que 'te'. A Tabela 6 mostra se nossa hipótese foi confirmada:

Tabela 6 - Frequência de uso de 'lhe' dativo conforme a estrutura verbal

\begin{tabular}{lcc}
\hline Forma & Ocorrências/Total & $\%$ \\
Simples & $109 / 215$ & 51 \\
Perifrástica & $64 / 105$ & 61 \\
\hline
\end{tabular}

Como se depreende da Tabela 6, nossa hipótese foi confirmada: 'lhe' foi mais recorrente na amostra com as formas perifrásticas do que com 
as formas simples, ocorrendo em $61 \%$ dos casos, de que são exemplos as seguintes ocorrências:

(35) Mais tarde vou LHE enviar um interesante dialogo que Jesus me deu. [C011]

(36) Desculpe em ter LHE tomado o tempo. [C034]

(37) estou LHE devendo duas cartas. [C044]

\subsubsection{Décadas}

As cartas da amostra cobrem o período que vai de 1940 a 2000, ou seja, as quatro últimas décadas do Século XX. Apresentamos agora como se deu o uso das formas clíticas 'te' e 'lhe' ao longo desse período:

Tabela 7 - Frequência de 'te' e 'lhe' por décadas do século XX

\begin{tabular}{ccc}
\hline Décadas & 'te' & 'Ihe' \\
$1940-50$ & $25(49 \%)$ & $26(51 \%)$ \\
$1960-70$ & $61(44 \%)$ & $77(56 \%)$ \\
$1980-90$ & $61(46 \%)$ & $70(54 \%)$ \\
Total & $147(46 \%)$ & $173(54 \%)$ \\
\hline
\end{tabular}

Como se depreende da Tabela 7, a alternância 'te' 'lhe' seguiu, nas cartas da amostra, sem muita oscilação, predominando sempre a forma 'lhe'. No primeiro período analisado (décadas de 1940 e 1950), a variação seguiu bastante acirrada, mas 'lhe' abriu uma diferença de 12 pontos percentuais sobre 'te' nas duas décadas seguintes, mas sofreu um leve declínio de uso nas décadas finais, embora ainda tenha permanecido predominante. 0 Gráfico 1 mostra a trajetória aqui descrita:
Gráfico 1 - Frequência de 'te' e 'lhe' por décadas do século XX

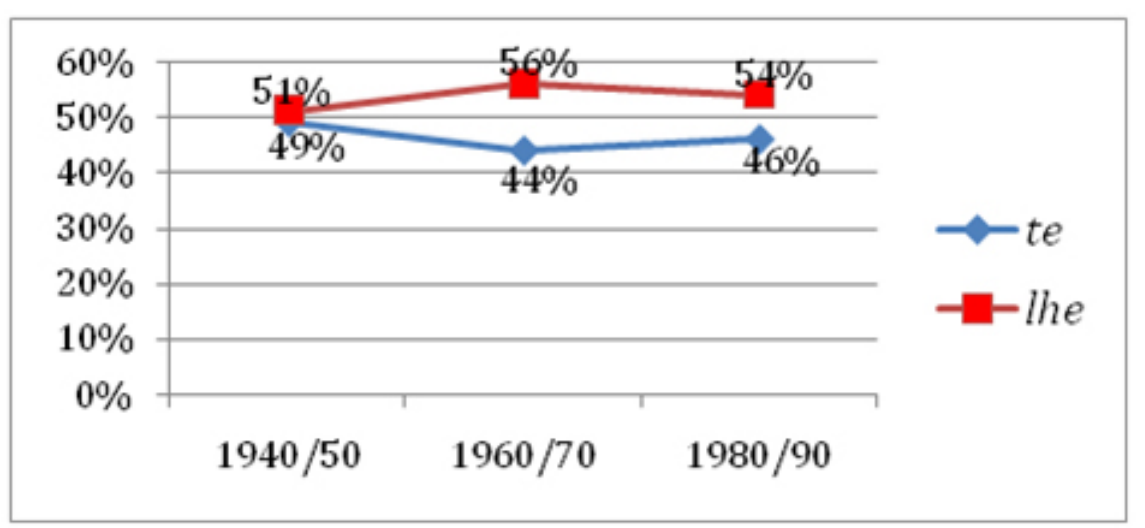

Antes de realizarmos as rodadas, supomos que, no período de 1940 a 1959, a forma predominante de clítico de $2^{\text {a }}$ pessoa fosse 'te', uma vez que o declínio do uso de 'tu' (do qual 'te' é a forma objetiva) em favor de 'você' (cuja forma objetiva é 'lhe') intensifica-se a partir da década de 1930, de acordo com a pesquisa de Duarte (1993). Além disso, Oliveira e Lopes (2007) mostraram que 'te' predomina de forma bastante acentuada sobre 'Ihe' em 97 cartas trocadas por um casal de noivos do Rio de Janeiro entre os anos 1936 e 1937. No entanto, 'lhe' revelou-se mais frequente do que 'te' nas cartas cearenses já na década de 1940 (51\%), em competição bastante acirrada com seu concorrente (49\%).

Quanto ao segundo período considerado, a análise mostrou que a frequência de 'lhe' (56\%) foi maior do que a de 'te' (44\%) nas cartas da amostra, sendo, portanto, 'Ihe' mais usual do que 'te'. Para esse período, havíamos presumido que as duas formas apresentavam frequência de uso equilibrada, como consequência da reanálise iniciada décadas antes, mas fomos contraditos pelos resultados. Nas décadas de 80 e 90 (54\% e 46\%, respectivamente) é onde há maior equilíbrio no uso dessas formas. 
Oliveira (2015, p. 88), em estudo realizado sobre a variação dos pronomes dativos de 2 a pessoa em cartas cariocas e fluminenses (1880-1980), observou uma tendência predominante ao uso do clítico 'te' em mais da metade da amostra em três quartos do período focalizado. Contudo, no período de 1956-1980, a forma pronominal 'te' sofre uma diminuição percentual de frequência, sendo nesse último período em que há maior equilíbrio no emprego das estratégias pronominais 'te' (30,0\%) e 'lhe' (24,5\%). Nas cartas do Ceará, predominou o clítico 'lhe' ao longo das décadas do século XX em estudo, apresentando uma distribuição regional, em termos quantitativos, diferente das cartas cariocas, o que parece refletir uma variação encontrada em alguns falares do nordeste (cf. BAGNO, 2011, p. 765).

\subsubsection{Sexo do remetente}

Das 186 cartas, 94 foram escritas por homens e 92 foram escritas por mulheres. A recorrência aos clíticos 'te' e 'lhe' com valor de 2 a pessoa foi 56 , $2 \%$ em cartas de homens e 43,8\% em cartas de mulheres.

Observando-se apenas o uso de 'lhe', percebemos que há uma leve diferença em seu uso por homens ou por mulheres:

Tabela 8 - Frequência de 'lhe' por sexo dos remetentes

\begin{tabular}{lcc}
\hline Sexo & Ocorrências/Total & $\mathbf{\%}$ \\
Homens & $95 / 173$ & 53 \\
Mulheres & $78 / 173$ & 56 \\
\hline
\end{tabular}

Como se pode observar, nas cartas da amostra, as mulheres usam levemente mais 'lhe' do que os homens. Dependendo do ponto de vista adotado, essa tendência confirma as hipóteses dos estudiosos: se considerarmos como mais provável ocorrer 'lhe' em vez de 'te' em cartas devido ao traço [+formal] atribuído àquela forma e a esse gênero textual em comparação com a fala, os dados comprovam o pensamento de Labov $(1990 ; 2001)$ que afirma que as mulheres tendem a usar com mais frequência variantes conservadoras. Assim também pensa Fisher (1958), para quem as mulheres tendem a conservar as formas linguísticas, evitando as inovações.

Porém, se considerarmos que 'te' é menos formal e, portanto, mais esperável em cartas pessoais trocadas entre amigos, os dados contradizem o que afirma Tannen (1990), a qual ressalta que mulheres são mais conservadoras e homens tendem a manifestar um estilo mais independente, sem muito envolvimento com seu interlocutor. Assim, os homens usariam menos 'te', que "indicaria mais aproximação e intimidade" (MONTEIRO, 1994), o que não aconteceu na amostra.

Nas cartas de homens da amostra, a forma 'te' ocorreu com mais frequência, como mostram trechos de duas cartas de amigo, uma escrita na década de 1940 (38) e outra na década de 1970 (39).

(38) Comunicu-TE o recebimento de sua carta, fiquei siente de tudo e muito satisfeito com as boas noticias, graças a Deus. [...] Pessu-TE ler esta carta a todos quantos se interessarem saber dos acontecidos. [...] No mas espera tambem novos mensageiros que TE mando juto a esta. [C001]

(39) quero dizer-TE que a falta de tempo é pouco, agora que sobrou um pouco para TE escrever. [...] Deus TE dê a luz e TE guie como cristão até os dias que ele TE proporcionar neste mundo [C102]

\section{Considerações finais}

Na produção das 186 cartas escritas por cearenses, o controle da alternância 'te' e 'lhe' como clíticos de 2 a pess. na função de dativo evidenciou as frequências de $46 \%$ e $54 \%$, respectivamente, o que mostra um predomínio de 'lhe' sobre 'te'. Tal predomínio parece-nos estar relacionado com a função 
primária desse pronome, uma vez que 'lhe' veio de îlli, dativo de îlle, "aquele” em latim.

Na amostra analisada, a posição enclítica favorece o uso de 'lhe' com $67 \%$ de uso, revelando-o conservador quanto à posição do complemento verbal prescrita pela tradição gramatical portuguesa. A forma 'te' apresentou $33 \%$ de uso nessa posição.

Quanto ao tipo semântico de verbo, os que mais favoreceram o uso do 'Ihe' dativo na amostra analisada foram, nesta ordem, os verbos relacionais ('pertencer a', 'caber a' etc.) - 100\%, os verbos existenciais ('ser', 'acontecer' etc.) - 67\%, e os verbos dicendi ('dizer', 'comunicar', 'contar' etc.) - 58\%.

Em relação à estrutura do verbo, 'lhe' foi mais frequente (61\%) nas formas perifrásticas, mas ficou numa competição muito acirrada com 'te' nas formas simples: $51 \%$ de 'lhe' e $49 \%$ de 'te'.

Considerando-se a variação 'te' 'lhe' ao longo das décadas, a amostra revelou que a competição entre as duas formas era bastante acirrada nos anos 1940 e 1950, mas 'lhe' foi mais frequente nas quatro últimas décadas do século XX (1960-70; 1980-90) nas cartas escritas por cearenses.

Finalmente, quanto ao sexo dos remetentes, as mulheres usaram mais 'Ihe' do que os homens, o que pode indicar que as remetentes possam seguir a tendência de associar o traço [+formal] de 'lhe' com a modalidade escrita.

\section{Referências}

ALMEIDA, G. de S. Quem te viu quem lhe vê: a expressão do objeto acusativo de referência à segunda pessoa na fala de Salvador. 2009. 193 fl. Dissertação (Mestrado em Linguística) - Instituto de Letras, Universidade Federal da Bahia, Salvador, 2009.

AMARAL, A. O dialeto caipira. São Paulo: Hucitec, 1955.

ANDRADE, M. L. da C. V. de O. Gênero social e norma linguística: estudo de formas de tratamento em cartas pessoais. In: PRETI, D. (Org.). Variações na fala e na escrita. São Paulo: Humanitas, 2011. p. 111-131.
ARAÚJO, F. J. N. A variação te/lhe em cartas pessoais de cearenses no século XX. 2014. 151 fl. Dissertação (Mestrado em Linguística) - Centro de Humanidades, Departamento de Letras Vernáculas, Universidade Federal do Ceará, Fortaleza, 2014.

ARAÚJO, F. J. N. ; CARVALHO, H. M. Te e lhe como clíticos acusativos de $2^{\underline{a}}$ pessoa em cartas pessoais cearenses. LaborHistórico, Rio de Janeiro, v. 1, n. 1, p. 62-80, jan.-jun. 2015

BAGNO, M. Gramática pedagógica do português brasileiro. São Paulo: Parábola Editorial 2011.

BIAZOLLI, C. C. Posição de clíticos pronominais em duas variedades do português: interrelações de estilo, gênero, modalidade e norma. 2016. $381 \mathrm{fl}$. Tese (Doutorado em Linguística e Língua Portuguesa) - Faculdade de Ciências e Letras, Universidade Estadual Paulista. Araraquara, 2016.

BROWN, R.; GILMAN, A. The Pronouns of Power and Solidarity. American Anthropologist, v. 4, n. 6, p. 24-39, 1960 .

CAVAlCANTE, C. R., O.; DUARTE, M. E. L.; PAGOTTO, E. G. Clíticos no século 19: uma questão de posição social? 2011 [no prelo]. Disponível em: <https://docs.google. com/viewer?a=v\&pid=sites\&srcid=ZGVmYXVsdGRvbWFpbnxzaWx2aWFyZXxneDoz MDJkMzRjNmU3MTVkZjg1>

COELHO, T. M. S. A sínclise dos substantivos pessoais átonos no português oral culto de Fortaleza: aspectos sociolinguísticos. Dissertação (Mestrado em Linguística) Departamento de Ciências Humanas, Universidade Federal do Ceará, 2003.

CONDE SILVESTRE, J. C. Sociolingüística histórica. Madrid: Editorial Gredos, 2007.

DUARTE, M. E. L. Do pronome nulo ao pronome pleno: a trajetória do sujeito no português do Brasil. In: ROBERTS, A.; KATO, M. A. (Org.). Português brasileiro: uma viagem diacrônica. Campinas: UNICAMP, 1993.

FISCHER, J. L. Social influences on the choice of linguistic variant. Word, n. 14, p. 47-56, 1958.

GUIMARÃES, T. A. A. S. Tu é doido, macho! - A variação das formas de tratamento no falar de Fortaleza. 2014. 237 fl. Dissertação (Mestrado em Linguística Aplicada) - Centro de Humanidades, Universidade Estadual do Ceará, Fortaleza, 2014.

LABOV, W. Language in the Inner City: Studies in the Black English Vernacular. Philadelphia: University of Alabama Press, 1972.

. The intersection of sex and social class in the course of linguistic change. In Language, Variation and Change, Cambridge, v. 2, n. 02, p. 205-254, 1990. 
Principles of Linguistic Change: Internal factors. Oxford/Cambridge: Blackwell Publishers, 1994.

Principles of Linguistic change. Vol. II: Social Factors. Oxford: Blackwell, 2001.

LOPES, C. R. S. Tradição e inovação: o sincretismo entre P2 e P3 em cartas do século XIX. In: LOBO, T. (Org.). VI Seminário do Projeto para a História do Português Brasileiro. Salvador: UFBA, 2004.

Pronomes pessoais. In: VIEIRA, S. R.; BRANDÃO, S. F. (Org.). Ensino de gramática descrição e uso. São Paulo: Contexto, 2007, p. 103-119.

LOPES, C. R. S.; CAVALCANTE, S. A cronologia do 'voceamento' no português brasileiro: expansão de você sujeito e retenção do clítico te. Linguística. Rio de Janeiro, v. 25, p. 30-65, jun. 2011

LOPES, C. R. S.; MACHADO, A. C. M. Tradição e inovação: indícios do sincretismo entre a segunda e a terceira pessoas nas cartas dos avós. In: LOPES, C. R. S. (Org.). A Norma Brasileira em Construção. Fatos linguísticos em cartas pessoais do século 19. Rio de Janeiro: Faculdade de Letras, UFRJ, FAPERJ. 2005, p. 45-66.

MACHADO, A. C. M. A implementação de "Você" no quadro pronominal: as estratégias de referência ao interlocutor em peças teatrais no século XX. Dissertação (Mestrado em Língua Portuguesa) - Faculdade de Letras, Universidade Federal do Rio de Janeiro, Rio de Janeiro, 2006, $108 \mathrm{p}$.

MARCUSCHI, L. A. Da fala para a escrita: atividades de retextualização. São Paulo: Cortez, 2001.

MENON, O. P. S. O sistema pronominal do português do Brasil. Letras, Curitiba, n. 44, p. 91-106, 1995.

MONTEIRO, J. L. Pronomes pessoais: subsídios para uma gramática do português do Brasil. Fortaleza: Edições UFC, 1994

MOTA, M. A. A variação dos pronomes 'tu' e 'você' no português oral de São João da Ponte $(M G)$. 2008. 125 fl. Dissertação (Mestrado em Linguística) - Universidade Federal de Minas Gerais, Uberlândia, 2008.

NASCENTES, A. Estudos filológicos. Rio de Janeiro: Academia Brasileira de Letras, 2003. OLIVEIRA, R.; LOPES, C. Retratos da mudança no sistema pronominal: Usos tratamentais cariocas na diacronia e sincronia. Edital Jovem Cientista da FAPERJ, Programa de Pós-Graduação em Letras - Universidade Federal do Rio de Janeiro, 2007. Disponível em: <http://www.sigmafoco.scire.coppe.ufrj.br/UFRJ/sigma/projetos/consulta/relatorio. stm?app $=$ PROJETOS\&codigo $=15418 \&$ buscas_cruzadas $=0 \mathrm{~N}>$
OLIVEIRA, T. L. de. Os pronomes dativos de $2^{\underline{a}}$ pessoa na escrita epistolar carioca. LaborHistórico, Rio de Janeiro, v. 1, n. 1, p. 81-98, jan.-jun. 2015

PAGOTTO, E. A posição dos clíticos em português: um estudo diacrônico. Dissertação (Mestrado em Linguística) - Universidade de Campinas (UNICAMP), 1992.

RAMOS, J. O uso das formas você, ocê e cê no dialeto mineiro. In: HORA, D. (Org.) Diversidade linguística no Brasil. João Pessoa: Ideia, 1997. p. 43-59.

RUMEU, M. C. de B. Para uma história do português do Brasil: formas pronominais e nominais de tratamento em cartas setecentistas e oitocentistas. Dissertação (Mestrado em Língua Portuguesa) - Programa de Pós-Graduação em Letras Vernáculas, Faculdade de Letras, Universidade Federal do Rio de Janeiro, 2004.

As relações de poder e de solidariedade na sociedade carioca os séculos XVIII e XIX. Revista Todas as Letras R (Mackenzie. online), v. 13, p. 115-126, 2011.

Língua e sociedade: a história do pronome "Você" no português brasileiro. Rio de Janeiro: Ítaca, 2013.

SALES, I. A. Aspectos linguísticos e sociais no uso de pronomes em cartas pessoais baianas. 2007. 385f. Dissertação (Mestrado em Língua Portuguesa) - Faculdade de Filosofia, Letras e Ciências Humanas, Universidade de São Paulo. São Paulo, 2007.

SANKOFF, D.; TAGLIAMONTE, S. A.; SMITH, E. Goldvarb X - A multivariate analysis application. Toronto: Department of Linguistics; Ottawa: Department of Mathematics. 2005.

SCHEI, A. A colocação pronominal do português brasileiro: a língua literária contemporânea. São Paulo: Humanitas FFLCH/USP. São Paulo, 2003.

SCHEIBMAN, J. Local patterns of subjectivity. In: BYBEE, J.; HOPPER, P. (Ed.). Frequency and the emergence of linguistic structure. Amsterdam/Philadelphia: John Benjamins Publishing Company, 2000. p. 61-90.

SERAFIM, R. L. Do Gerúndio ao Gerundismo: Mudança e Preconceito Linguístico. $81 \mathrm{fl}$ Monografia (Bacharelado em Letras) - Universidade Federal de Brasília, Salvador, 2008.

SILVA, E. N. A., A variação entre as formas pronominais da segunda pessoa "tu" e "você" em cartas de 1930. In: SILEI, 2., 2011, Uberlândia. Anais... Uberlândia: EDUFU, 2011 p. 132-153.

SOTO, E. U. M. S. Variação/Mudança do pronome de tratamento alocutivo: uma análise enunciativa em cartas brasileiras. Tese (Doutorado em Linguística) - Faculdade de Ciências e Letras, Universidade Estadual Paulista, Araraquara, 2001. 
SOUZA, C. D. Eu te amo, eu lhe adoro, eu quero você: a variação das formas de acusativo de $2^{2}$ pessoa em cartas pessoais (1880-1980). 2014. 156 fl. Dissertação (Mestrado em Letras) - Programa de Pós-Graduação em Letras Vernáculas, Faculdade de Letras, Universidade Federal do Rio de Janeiro, 2014.

TANNEN, D. You just don't understand: women and men in conversation. New York: William Morrow and Company Inc., 1990.

WEINREICH, U.; LABOV, W.; HERZOG, M. I. Fundamentos empíricos para uma teoria da mudança linguística. São Paulo: Parábola Editorial, 2006 [1996].

Recebido em 29/08/2016

Aceito em $27 / 0$ 